\title{
Are workplace health promotion programs effective at improving presenteeism in workers? a systematic review and best evidence synthesis of the literature
}

Carol Cancelliere ${ }^{1,2^{*}}$, J David Cassidy ${ }^{2,3,4}$, Carlo Ammendolia ${ }^{4,5,6}$ and Pierre Côtée $2,3,4$

\begin{abstract}
Background: Presenteeism is highly prevalent and costly to employers. It is defined as being present at work, but limited in some aspect of job performance by a health problem.

Workplace health promotion (WHP) is a common strategy used to enhance on-the-job productivity. The primary objective is to determine if WHP programs are effective in improving presenteeism. The secondary objectives are to identify characteristics of successful programs and potential risk factors for presenteeism.

Methods: The Cochrane Library, Medline, and other electronic databases were searched from 1990 to 2010. Reference lists were examined, key journals were hand-searched and experts were contacted. Included studies were original research that contained data on at least 20 participants ( $\geq 18$ years of age), and examined the impacts of WHP programs implemented at the workplace. The Effective Public Health Practice Project Tool for Quantitative Studies was used to rate studies. 'Strong' and 'moderate' studies were abstracted into evidence tables, and a best evidence synthesis was performed. Interventions were deemed successful if they improved the outcome of interest. Their program components were identified, as were possible risk factors contributing to presenteeism.
\end{abstract}

Results: After 2,032 titles and abstracts were screened, 47 articles were reviewed, and 14 were accepted (4 strong and 10 moderate studies). These studies contained preliminary evidence for a positive effect of some WHP programs. Successful programs offered organizational leadership, health risk screening, individually tailored programs, and a supportive workplace culture. Potential risk factors contributing to presenteeism included being overweight, a poor diet, a lack of exercise, high stress, and poor relations with co-workers and management. Limitations: This review is limited to English publications. A large number of reviewed studies (70\%) were inadmissible due to issues of bias, thus limiting the amount of primary evidence. The uncertainties surrounding presenteeism measurement is of significant concern as a source of bias.

Conclusions: The presenteeism literature is young and heterogeneous. There is preliminary evidence that some WHP programs can positively affect presenteeism and that certain risk factors are of importance. Future research would benefit from standard presenteeism metrics and studies conducted across a broad range of workplace settings.

\footnotetext{
* Correspondence: ccancell@uhnresearch.ca

${ }^{1}$ Master of Public Health Program, Faculty of Graduate Studies, Lakehead

University, Thunder Bay, Ontario, Canada

Full list of author information is available at the end of the article
} 


\section{Background Definitions}

A healthy and productive workforce is critical for economic success and population health. Illness at the workplace can result in lost productivity, which arises from two sources: absenteeism and presenteeism. Absenteeism refers to an employee's time away from work due to illness or disability [1]. Presenteeism refers to the decrease in productivity in employees whose health problems have not necessarily led to absenteeism and the decrease in productivity for the disabled workers before and after their absence period [2]. It is defined as being present at work, but limited in some aspects of job performance by a health problem, and it is often a hidden cost for employers [3]. It includes time not spent on job tasks and decreased quality of work (e.g. product waste and product defects) [4]. Absenteeism and presenteeism are part of a continuum within which workers likely transition back and forth over time [5].

Health promotion in the workplace is defined as preventing, minimizing and eliminating health hazards, and maintaining and promoting work ability [6]. Worker health and wellness is maintaining a balance of the physical, mental and social ingredients, as well as health habits associated with good physical condition, energy and vitality [6].

\section{Presenteeism: a relatively new field}

Presenteeism emerged as a new business issue in the 1990's [7]. It is becoming a significant challenge to maintain a healthy and productive workforce for developed countries due to an increasing number of people affected by chronic health conditions and an aging workforce that is more likely to be affected by these conditions. Subsequent rising health care costs and an increasing awareness of presenteeism losses are escalating the demand for health promotion programs for working populations [8].

Research on interventions to improve presenteeism is still relatively new compared with other workplace issues such as healthcare costs and absenteeism [9-11]. Most of the literature on presenteeism has investigated its measurement [3].

\section{Measurement of presenteeism}

Currently, there is no universal agreement on the most appropriate method for measuring or monetizing presenteeism [1,12]. It is typically measured as the costs associated with reduced work output, errors on the job, or failure to meet company production standards [13]. It is difficult to value presenteeism economically because past studies use different measures of presenteeism, include different populations of workers and use various methods to assign dollar values to their losses. Nevertheless, it appears that economic costs are considerable $[1,14,15]$.

Several self-report instruments have been developed to measure presenteeism across various types of jobs and organizations [1,16-18]. These are useful especially when it is difficult to obtain objective data regarding particular characteristics of a workplace or profession (e.g. the number of parts manufactured). Evidence of their psychometric properties has been reported in varying degrees [3,5,14,17-23]. Some common tools with good psychometric properties include the Work Limitations Questionnaire (WLQ) [20,24], Work Productivity and Activity Impairment (WPAI) [25,26], and the Stanford Presenteeism Scale (SPS) [20,27]. These tools assess presenteeism with the assessment of perceived impairment approach, where employees are asked how much their illnesses hinder them in performing common mental, physical, and interpersonal tasks and in meeting job demands.

\section{WHP programs}

WHP programs vary considerably in size and composition, and they have evolved significantly over the past 30 years [28-30]. However, whether or not programs can improve workplace productivity has yet to be determined. While containing health care-related costs and absenteeism have been important strategies for companies, greater gains may be realized by improving on-thejob productivity and investing in preventive and early intervention services [29,31-36].

The primary objective of our study is to review and scientifically appraise the literature on WHP programs to see if they are effective in improving presenteeism among employees. The secondary objectives are to identify components of successful WHP programs and to identify risk factors for presenteeism.

\section{Methods}

\section{Literature search}

The scientific literature published between 1990 and January, 2010 was systematically searched. Primary sources were the electronic databases of The Cochrane Library, Medline, Embase, CINAHL Plus, NLM Gateway, PsychINFO, Evidence in Health and Social Care, AMED and the Trip Database (Additional file 1). The search strategy was reviewed by a reference librarian. Additionally, the reference lists of all relevant studies were examined, and three of the most relevant journals were hand-searched between January, 2005 and February, 2010 (i.e. Journal of Occupational and Environmental Medicine, Ergonomics, and Journal of Industrial Medicine). A Google search for unpublished literature 
was conducted in January, 2010 using the search terms presenteeism, health promotion, and workplace. Government and other relevant websites were scanned. Experts and organizations involved with WHP and presenteeism were contacted (Additional file 2).

\section{Screening the literature}

All citations identified through the search strategy were screened. These included English-language reports, published reports of original research (randomized controlled and controlled trials, cohort, pre-post, and ecological studies), systematic reviews, meta-analyses, conference proceedings, government reports, guidelines, and unpublished gray literature manuscripts. To be included, studies had to be original research that contained data on at least 20 human participants; focused on adults 18 years of age or older; and examined WHP programs including all types of measures aimed at promoting health and wellness, or reducing the risk of illhealth. These could be targeted at behavioural, physiological, organizational or environmental changes. The intervention had to be implemented at the workplace but activities were allowed to occur elsewhere. For example, risk factor screening and education could occur at the workplace, but workers were allowed to use external exercise facilities, or seek additional medical attention. The intervention also had to be described in sufficient detail. Exclusion criteria included studies examining only military personnel; return-to-work studies; narrative, editorial, or clinical reviews; opinion papers, editorials, and letters to the editor; studies where interventions were not implemented at the worksite; studies where productivity outcomes were not measured or specified; studies which grouped productivity outcomes together, such as presenteeism and absenteeism, and the results could not be evaluated specifically for presenteeism changes; and studies that measured productivity only in terms of lost earnings. All relevant systematic reviews and meta-analyses were screened to ensure that primary studies were not missed.

\section{Critical review of the literature}

Relevant primary studies were assessed for methodological quality using a tool developed and tested by the Effective Public Health Practice Project (EPHPP) EPHPP Quality Assessment Tool for Quantitative Studies (Additional file 3) [37,38]. It consists of six criteria: selection bias, allocation bias, control of confounders, blinding of outcome assessors, data collection methods, and withdrawals and dropouts. Reviewers were asked to rate each criterion as 'weak', 'moderate', or 'strong'. A final global rating of each study was subsequently determined. The tool has demonstrated reliability, content and construct validity, and the ability to adapt current methods for systematic literature reviews of effectiveness to questions related to public health. The test-retest reliability of the EPHPP is good (i.e. Cohen's Kappa of $0.74)$. Content validity was established by having six experts review the questionnaire, and it was independently tested on 10 primary studies by four experts in critical appraisal and community health. Construct validity was shown through comparisons with another highly rated instrument, the Guide to Community Preventive Services [39]. The EPHPP is relatively easy to use and an accompanying dictionary clarifies any questions related to the components. Two reviewers independently performed in-depth reviews for each study. A consensus method was used to solve disagreements about study selection and methodological quality. A third reviewer was consulted if disagreement persisted.

\section{Data extraction and synthesis/analysis}

Studies were considered scientifically admissible if they were rated as moderate or strong, or scientifically inadmissible if they were rated as weak, had fatal biases or other important methodological flaws. Table 1 summarizes the criteria for this rating classification [38]. Information was extracted from each admissible study on: (1) country and workplace, (2) study design, (3) characteristics of participants, (4) inclusion and exclusion criteria, (5) intervention(s) and control(s), (6) outcome measurements and follow up periods, and (7) key findings and limitations (Additional files 4 and 5). The heterogeneity of the populations, interventions and outcome measures made it too difficult to compare the studies. A best evidence synthesis was performed and is based only on the results of the strong and moderate studies [40]. Interventions were deemed successful if they improved the outcome of interest and their program components were subsequently identified. Possible risk factors contributing to presenteeism were identified through the literature review.

\section{Results}

After applying the inclusion and exclusion criteria to 2,032 identified titles and abstracts, 47 articles were judged to be relevant and were critically reviewed. Thirty percent of these articles (i.e. 14 unique studies) were deeemed scientifically admissible (Figure 1). Four studies were given a strong rating and 10 studies were rated moderate (Table 1). These studies form the basis of the findings and consist of five randomized controlled trials (RCTs), five cluster RCTs, one interrupted time series study, one crossover designed study, one pre-post study, and one quasi-experimental study (Additional files 4 and 5). The source populations for the studies varied geographically, with three studies from The Netherlands, three from the U.S., two from Japan, two from 
Table 1 Quality Assessment Components and Ratings for EPHPP Instrument

\begin{tabular}{|c|c|c|c|}
\hline Components & Strong & Moderate & Weak \\
\hline Selection bias & $\begin{array}{c}\text { Very likely to be representative of target } \\
\text { population; greater than } 80 \% \text { participation } \\
\text { rate }\end{array}$ & $\begin{array}{c}\text { Somewhat likely to be representative of } \\
\text { target population; } 60-79 \% \text { participation } \\
\text { rate }\end{array}$ & All other responses or not stated \\
\hline Design & $\begin{array}{c}\text { Randomized Control Trial, Clinical Control } \\
\text { Trial }\end{array}$ & $\begin{array}{l}\text { Cohort analytic, case-control, cohort, or } \\
\text { interrupted time series }\end{array}$ & All other designs or design not stated \\
\hline Confounders & Controlled for at least $80 \%$ of confounders & Controlled for $60-79 \%$ of confounders & $\begin{array}{c}\text { Confounders not controlled for, or not } \\
\text { stated }\end{array}$ \\
\hline Blinding & $\begin{array}{l}\text { Blinding of outcome assessor \& participants } \\
\text { to intervention \&/or research question }\end{array}$ & $\begin{array}{c}\text { Blinding of either outcome assessor or } \\
\text { participants }\end{array}$ & $\begin{array}{c}\text { Outcome assessor \& participants are } \\
\text { aware of intervention \&/or research } \\
\text { question }\end{array}$ \\
\hline $\begin{array}{l}\text { Data } \\
\text { collection } \\
\text { methods }\end{array}$ & Tools are valid \& reliable & Tools are valid but reliability not described & No evidence of validity or reliability \\
\hline $\begin{array}{l}\text { Withdrawals } \\
\& \text { dropouts }\end{array}$ & Follow-up rate of $>80 \%$ of participants & Follow-up rate of $60-79 \%$ of participants & $\begin{array}{l}\text { Follow-up rate of }<60 \% \text { of participants } \\
\text { or withdrawals \& dropouts not described }\end{array}$ \\
\hline
\end{tabular}

Copyright 2004 by John Wiley and Sons. Adapted with permission of the author.

the U.K., and one each from Canada, Denmark, Finland, and Sweden.

\section{Interventions demonstrating positive effects on presenteeism}

Interventions were deemed successful if they improved the outcome of interest (i.e. presenteeism). Overall, ten interventions demonstrated preliminary evidence of promising effects on presenteeism in their respective employee populations and work settings (Additional files 4, 5 and 6).

Strong evidence for this was found in two studies (Additional files 4 and 6). The first involved worksite exercise [41], and the second investigated the impact of a supervisor education program regarding mental health promotion [42].

The remaining eight studies provided moderate evidence of positive intervention effects (Additional files 5 and 6). These interventions consisted of "A Lifestyle Intervention Via Email” (Alive!) [43], extra rest break time for workers engaged in highly repetitive work [44], a multi-disciplinary occupational health program [45], a multi-component health promotion program [46], participatory processes $[47,48]$, exposure to blue-enriched light (vs. white light) [49], and a telephone intervention program for depressed workers [50].

\section{Interventions not demonstrating improvement in presenteeism}

Interventions were deemed unsuccessful if they did not improve the outcome of interest (i.e. presenteeism). Four interventions were unsuccessful at improving presenteeism in their specific employee populations and work settings (Additional files 4 and 5). Two of these were rated as strong [51,52] and two as moderate $[53,54]$. These consisted of the implementation of a computer mouse with a feedback signal to prevent hovering behaviour [54], a multi-dimensional program for low back pain prevention [51], specific resistance training and all-around physical exercise [53], and worksite exercise/reduced work hours [52].

\section{Successful vs. unsuccessful interventions}

Of the 10 successful interventions, three were delivered by a health professional (Additional files 4, 5 and 6): physiotherapists, occupational health nurses [41], psychologists [42], or occupational health physicians [45]. Two were delivered using a participatory approach, which consists of teamwork among employees, managers, human resources personnel, and researchers $[47,48]$. One was delivered over the telephone by mental health clinicians [50], one was delivered by email/internet [43], one was an organizational change (i.e. rest break schedule) [44], and one was an environmental change (i.e. lighting) [49]. A final successful intervention utilized a mixed delivery method consisting of email, paper-based packs, and worksite seminars [46]. Of the four unsuccessful interventions (Additional files 4 and 5), one was delivered by a health professional (i.e. physiotherapist) [51], one was delivered by an experienced fitness instructor [53], one was an equipment change (i. e. computer mouse) [54], and the final one consisted of an organizational change (i.e. work hours allocated to mandatory physical exercise) [52].

Some workplaces screened workers prior to intervention. One of the most common screening methods is the health risk assessment (HRA). It includes the assessment of personal health habits and risk factors, estimation of future risk of adverse health outcomes, and feedback in the form of education and counselling to alter risk factors [55]. It is valuable for identifying high-cost claimants; targeting individual program participation and measuring 


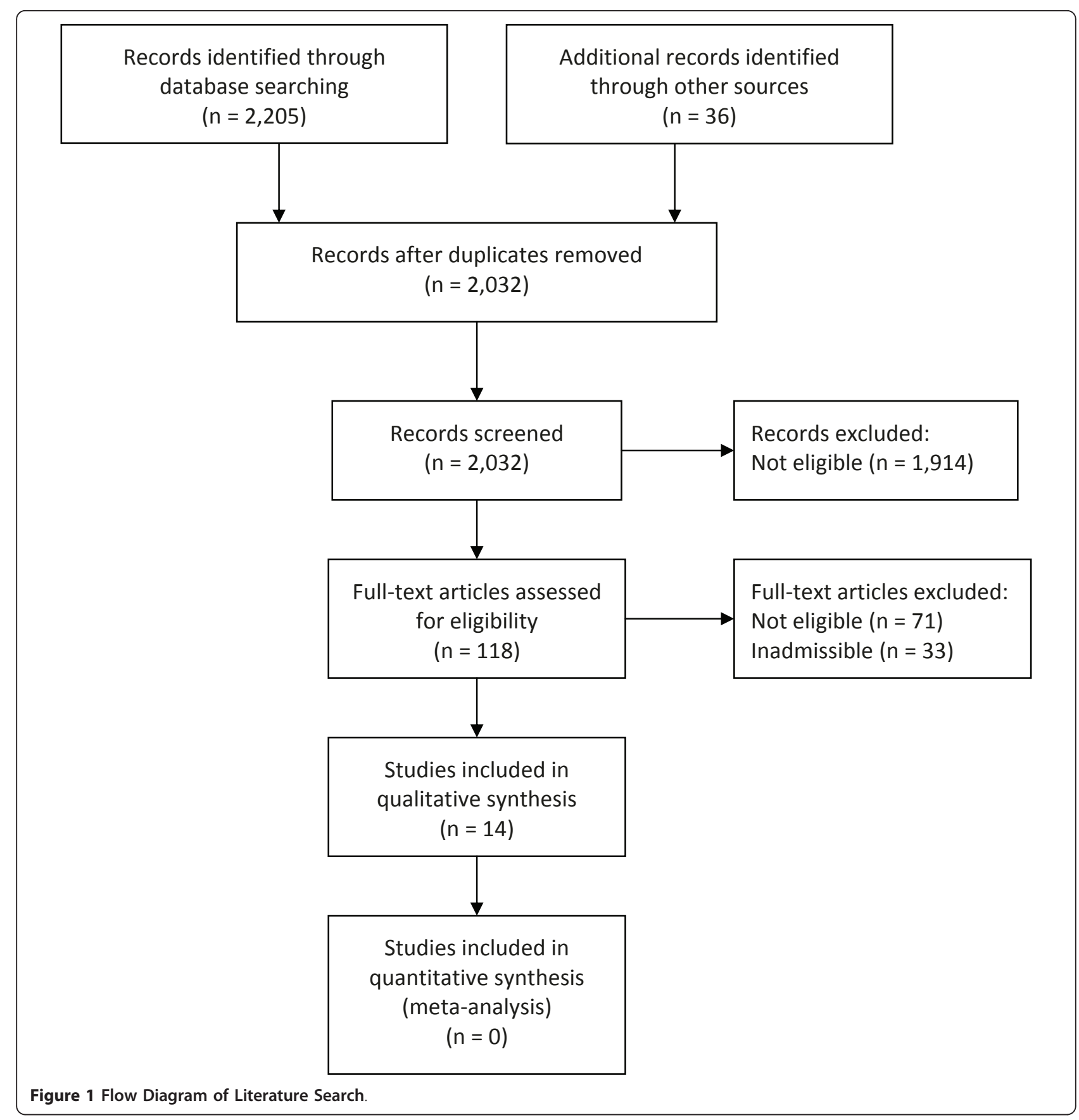

and tracking individual behaviours that effect health care costs, absenteeism and presenteeism [7,55]. Seven of the 10 successful interventions used screening methods (Additional file 6), consisting primarily of HRAs, or other questionnaires/assessments [41,43,45-48,50]. Two of these seven interventions utilized a participatory approach, whereby screening is inherent in the process (i. e. teams first identify problems and needs, then develop solutions) $[47,48]$. On the other hand, screening methods were used in only one of the four unsuccessful interventions [52].

Seven of the 10 successful interventions tailored their programs to address participant needs (Additional file 6) $[41,43,45-48,50]$, whereas tailoring occurred in only half of the unsuccessful interventions [51,53]. Finally, only one of the 10 successful interventions used an incentive (i.e. lottery tickets) (Additional file 6) [46]. Incentives were not used in any of the unsuccessful interventions. 


\section{Summary of results of strong vs. moderate studies}

Four of the 14 admissible studies were rated as strong (Additional file 4). However, there still existed some bias with respect to thorough reporting of withdrawals and drop-outs [51], data collection methods [42], and participant selection [52]. All four studies also showed a risk of bias with respect to blinding of outcome assessors and/or participants, as well as intervention integrity $[41,42,51,52]$.

Three of these four studies were cluster RCTs and the other was a RCT. Two of the four interventions improved presenteeism (Additional files 4 and 6) and involved worksite exercises [41] and a supervisor mental health education program [42]. Both were delivered by health professionals. Workers were screened and the intervention was individually tailored in only one of them [41]. Employee incentives were not used in either intervention.

In two of the four strong studies, the interventions did not improve presenteeism (Additional file 4). These included a low back pain prevention program [51], and a worksite exercise/reduced work hours program [52]. Only one of these was individually tailored and delivered by a health professional [51]. Neither intervention involved worker screening, or the use of incentives.

Of the 14 admissible studies, 10 were rated as moderate evidence and demonstrated similar biases although to a greater degree than the four higher quality studies (Additional file 5). These consist of four RCTs, two cluster RCTs, one crossover design, one interrupted time series, one pre-post study, and one quasi-experimental study. Eight of these 10 interventions improved presenteeism (Additional files 5 and 6). These include Alive (A Lifestyle Intervention Via Email) [43], extra rest break time [44], two participatory interventions [47,48], lighting changes [49], a multi-component health promotion program [46], a telephone support program [50], and an occupational health program [45]. Delivery methods varied and were executed by: health professionals $[45,50]$, participatory methods $[47,48]$, the internet [43], mixed methods [46], an organizational change [44], and an environmental change [49]. Six of these eight successful interventions involved employee screening methods $[43,45-48,50]$. These six, in addition to the one by Blangsted and colleagues [53], were individually tailored. Only one of the eight interventions used an employee incentive [46].

Two of the 10 moderate studies were not successful at improving presenteeism (Additional file 5) and consisted of exercise [53], and a computer mouse with a feedback signal to prevent hovering behaviour [54]. Neither of these were delivered by health professionals. One was delivered by a fitness intructor [53], and the other involved an equipment change [54]. Only one intervention was individually tailored [53]. Workers were not screened and incentives were not used in either intervention.

A secondary objective was to identify components of WHP programs successful at improving presenteeism. We found preliminary evidence to support the use of one or more of the following: involving employees' supervisors/managers in WHP programs $[42,45,47,48]$, targeting organizational and/or environmental factors to influence behaviour $[41,42,44,45,47-49]$, screening workers prior to intervention using HRAs or other methods [43,45-48,50], improving supervisor/manager knowledge regarding mental health in the workplace [42], allowing physical exercise to occur during working hours [41], and individually tailoring programs $[41,43,45-48,50]$. Grounding interventions in behaviour change models to help reinforce desirable lifestyle behaviours [43], using participatory approaches with high employee involvement to develop interventions [47,48], and increasing the frequency and duration of rest breaks for workers required to stand for prolonged periods [44] were also helpful. Interventions can be delivered by various modes including telephone, email/internet, seminars, paperbased literature [43,46]; participatory teams [47,48]; organizational changes [44]; environmental changes [49]; and by various health professionals $[41,42,45,50]$.

Another secondary objective was to understand risk factors affecting presenteeism. Several factors were reported in the literature such as being overweight, having a poor diet, smoking, a lack of physical exercise, high stress, poor relations with co-workers and management, and poor physical work environments [1-3]. Health conditions affecting worker presenteeism were also reported and included arthritis, allergies, migraine, chronic pain, diabetes, hypertension, gastro-intestinal conditions, gastro-esophageal reflux disease, musculoskeletal disorders, respiratory disorders, mental health problems such as depression and anxiety, cancer, cardiovascular disease, and metabolic syndrome [1-3,12,13,15]. In general, these risk factors and health conditions can decrease worker productivity by causing pain and fatigue, and by reducing physical and mental capacities.

\section{Discussion}

This systematic review is an important contribution to the field of WHP and presenteeism and builds on previous research in this area. Two previous studies systematically reviewed related literature. Riedel and colleagues [9] searched all English language primary studies, reviews, concept articles, and background articles related to WHP and its effect on worker productivity from 1993 through 1998. They reviewed 146 articles, but found that when productivity loss information was available, it was mostly measured in terms of absenteeism rather than presenteeism. They identified depression screening, 
back pain exercise programs, smoking cessation, influenza vaccination, and care-seeking programs for minor illnesses as interventions that could provide short term gains in productivity. They concluded that two major challenges to the success of WHP programs were getting high participation rates and maintaining behaviour change over time.

Kuoppala and colleagues [10] studied the association between WHP and job well-being, work ability, absenteeism, and early retirement. Work ability was defined as employees' physical, psychological, and social capacity to work and depends both on their health and the contents of their work. They systematically searched and critically evaluated the literature in Medline and PsychINFO from 1970 to 2005. Out of 1312 references, 46 original studies and systematic reviews were included in their analysis. They found moderate evidence that WHP involving exercise increases work ability. However this finding was based on a study with a weak methodological design and potential biases in participant selection, confounding, blinding, and withdrawals and dropouts [11].

Our findings draw on a larger pool of relevant studies compared to Riedel and colleagues [9]. The review by Kuoppala and colleagues [10] ended in 2005, and involved a broader search including the link between WHP and well-being, work ability, absenteeism, as well as early retirement. Our study updates this search and narrows the focus to analyze only studies investigating the effects of WHP on one or more aspects of presenteeism/worker productivity. Compared to the work of Kuoppala and colleagues [10], our review included more search terms in addition to 'work ability', in an attempt to capture as many presenteeism studies as available (e. g. 'productivity', 'work limitation', 'work impairment', 'presenteeism', 'work performance', and 'work disability') (Additional file 1). We also searched additional databases and the gray literature, and contacted experts in the presenteeism field (Additional file 2).

Consistent with findings from both of the above studies $[9,10]$, our results show that exercise is beneficial in improving presenteeism. Although it is not known which specific type of exercise program is best, if any. Riedel and colleagues found evidence to support back pain exercise programs [9]. Kuoppala and associates identified support for supervised worksite exercise, consisting of aerobic and muscular fitness (one hour, twice per week for nine months). We found evidence to support selfdirected worksite exercise (one hour per week for nine months) [41]. Addressing depression and mental health at the workplace was found to be useful in our review, in line with findings by Riedel and colleagues [9]. Again, the specifics of the interventions varied and consisted of depression screening [9], an educational mental health promotion program for supervisors [42], and a depression outreach-treatment telephone program [50].

Our findings suggest, and others agree [10,33] that WHP should target psychosocial factors in addition to physical factors at work. Indeed, the participatory interventions analyzed in our review that addressed both psychosocial and physical factors were beneficial $[47,48]$. Creating a positive work environment can help to reduce health risks and improve productivity in the workplace.

Our review adds to the existing literature and is useful to employers, health care providers and policy makers. We found additional evidence to support lifestyle behaviour interventions, occupational/multi-component health programs, participatory programs, lighting changes and extra rest break time. We also found other program components that have positive effects on presenteeism such as screening workers prior to intervention, as well as providing workers with incentives and tailored interventions.

In the studies we reviewed, the original investigators described similar ways in which improvements in presenteeism may have been (further) realized in their respective studies. WHP interventions should provide incentives to employees (e.g. monetary) to improve participation and response rates as well as intervention adherence [43]. Interventions such as exercise programs should be longer, more intense and frequent $[41,47,53]$; and they should be based on a theory such as the behaviour change model [43]. Longer follow-up periods are needed to determine whether intervention effects improve, or persist over the long term [42,46-48,52]. Care must be taken to ensure that interventions are appropriate for specific employee populations and work tasks. For example, individually tailored interventions may not be appropriate in team-based job tasks [51]. Additional resources such as more support, training or counselling sessions, may be required to make interventions more robust $[41,51,53]$. Moreover, broader actions may be needed such as organizational and environmental interventions that include a multi-professional approach $[41,45,47]$.

Presenteeism and absenteeism are often inter-related. Individuals may only be absent below a certain threshold of illness and quality of life. This threshold may depend on the working situation (e.g. manual or white collar jobs), the type of illness (e.g. mental or physical), the degree of coping and the support available in the worker's social network [3]. Thus, the continuum between absenteeism and presenteeism can vary highly over time. Furthermore, an intervention might be successful in reducing work absence, but only at the expense of a rise in presenteeism, if the health problem is not properly dealt with [56]. 
Preliminary yet promising effects were found for various WHP programs. However, it is important to mention that some of these program components were also present in the four studies that did not demonstrate improved presenteeism (Additional files 4 and 5). These include physical activity [52,53], ergonomic changes [54] and a multi-dimensional prevention program [51]. Therefore, a distinction needs to be made between theory failure and program failure [57]. In these four unsuccessful interventions, it is likely that program failure occurred (e.g. the intervention was not implemented properly, or compliance was poor). Theory failure would imply that physical activity, ergonomic changes, or other prevention programs are not effective. However, we did find some of these components to be effective in our review (Additional file 6).

\section{Review strengths and limitations}

This review has several strengths. The best available evidence was systematically gathered, appraised, and synthesized. Limiting the findings to studies of better methodological quality is a notable strength that builds on past results $[9,10]$. All steps of our comprehensive review were explicitly reported, thereby making the process more transparent and reproducible. Our findings are reported in compliance with PRISMA guidelines (Preferred Reporting Items for Systematic Reviews and Meta-Analysis) [58].

Our study has limitations. While the search was extensive, it is limited to the literature available as of January, 2010 and to English publications. Only 14 of 47 articles reviewed were scientifically admissible, which limits the number of higher quality studies to draw inferences from. The other studies were inadmissible because of bias. Included studies also had risk of bias, but to a lesser extent. Common problems encountered included selection bias, or the selection criteria to get into the study were not described [59-81]. Many of the inadmissible studies had poor response and participation rates (i.e. less than 60\%) [59-61,67,69,72,77,82]. Other studies did not consider, or report on, common confounding factors such as gender, age, education, and health status [59,60,62-64,66-71,74-79,82-90]. Insufficient blinding of the assessors and/or the participants was observed in several studies [59-61,63,64,69,70,72,75,79-81,83-85,88-91]. Information bias is likely in a number of the studies as some of the data collection tools have not been shown to be reliable and valid [59,61,63-65,72,78-82,85,87-90]. Finally, various studies did not adequately report withdrawal and/or drop-out rates, or had unacceptably high rates (i.e. follow-up rate less than 60\%) with little to no examination of differences between study participants and nonparticipants [59-62,64,65,68-71,73-75,82,83,88,89].
Presenteeism is an evolving field and is difficult to measure. The uncertainties and inconsistencies surrounding its measurement may be one of the biggest limitations regarding the usefulness of this review. All of the current instruments have drawbacks and several significant measurement issues have been raised $[1,3,13,14,18,92]$; Edington DW, personal communication, March 2010]. Only a few of the instruments have been validated against objective measures of productivity, such as the number of calls made in a call centre, or the number of parts assembled in a manufacturing plant. This is easiest to do when dealing with piecework, but is much more difficult when concrete, measureable output is not available, as with jobs in the knowledge sector, or when dealing with team work where the presenteeism of a single team member may affect the job performance of the group. Additionally, each instrument measures a different quality of presenteeism (e.g. quality or quantity of work), making results difficult to compare. Finally, indirect costs faced by employers having to respond to reduced productivity need to be taken into account, including hiring new or temporary staff, training staff, paying overtime to other employees, and dealing with lost revenue, to name a few.

\section{Conclusions}

WHP represents one of the most significant strategies for enhancing the productivity of workers at a time when their average age is increasing [93]. Despite longstanding advocacy for comprehensive worksite programs, we need more empirical evidence to link these strategies to improvements in health and productivity [35]. We found preliminary evidence of a positive effect for some programs, identified their components and some contributing risk factors for presenteeism. Caution is needed in interpreting these results due to heterogeneous response/participation rates, interventions, intervention delivery methods, presenteeism measurement tools, employee populations, geographical and workplace settings, and inclusion and exclusion criteria. Interestingly, it has been stated that the most important issue for organizations to address is not whether or not WHP programs should be implemented to reduce risks and enhance productivity, but rather how such programs should be designed, implemented, and evaluated to achieve optimal results [47]. Further implementation research is needed in this area.

\section{Additional material}

Additional file 1: Search Strategy. This file provides the complete list of search terms used to search The Cochrane Library, Medline, Embase, and other databases. 
Additional file 2: Experts, Organizations, \& Websites Contacted. This file provides a list of experts, organizations, and websites contacted that deal with presenteeism and/or workplace health promotion.

Additional file 3: Quality Assessment Tool for Quantitative Studies This file contains the Effective Public Health Practice Project's (EPHPP) tool used to assess the methodological quality of studies that passed relevance screening for inclusion in this review.

Additional file 4: Data Extraction Results for Included Studies Rated Strong. This file contains the data extraction results for the 4 studies included in this review that were rated as strong after being assessed for methodological quality. Data includes authors, date of publication, country, study design, setting, participants, interventions, outcome measurements, and key findings and limitations.

Additional file 5: Data Extraction Results for Included Studies Rated Moderate. This file contains the data extraction results for the 10 studies included in this review that were rated as moderate after being assessed for methodological quality. Data includes authors, date of publication, country, study design, setting, participants, interventions, outcome measurements, and key findings and limitations.

Additional file 6: Description of Interventions Demonstrating Positive Effect on Presenteeism. This file contains detailed descriptions of the 10 interventions which demonstrated a positive effect on presenteeism. Data includes intervention goals, intervention delivery methods; and indicates whether subjects were screened, whether interventions were individually tailored, and whether incentives were used.

\section{Acknowledgements}

The authors thank Anne Taylor-Vaisey MLS, and Deanne Collier from the Canadian Memorial Chiropractic College for their assistance with searching and retrieving the literature. The authors thank William Montelpare, lan Newhouse, and Dee W. Edington for reviewing the manuscript and providing helpful comments. The authors thank the Ontario Chiropractic Association, the Ministry of Health and Long-term Care, and the Institute for Work and Health for helping to fund the research.

\section{Author details}

'Master of Public Health Program, Faculty of Graduate Studies, Lakehead University, Thunder Bay, Ontario, Canada. 'Division of Health Care and Outcomes Research, Toronto Western Research Institute, Toronto Western Hospital, Ontario, Canada. ${ }^{3}$ Division of Epidemiology, Dalla Lana School of Public Health, University of Toronto, Ontario, Canada. ${ }^{4}$ Department of Health Policy, Management and Evaluation, Faculty of Medicine, University of Toronto, Ontario, Canada. Institute for Work and Health, Toronto, Ontario, Canada. ${ }^{6}$ Department of Medicine, Division of Rheumatology, Mount Sinai Hospital, Toronto, Ontario, Canada.

\section{Authors' contributions}

All authors formulated the research question, sketched the research design and critically analyzed relevant studies. JDC supervised and coordinated the study. CC reviewed the existing literature, performed the literature search, and drafted the manuscript. CC and CA analyzed the majority of the studies. JDC and PC revised the manuscript substantially. All authors read and approved the final manuscript.

\section{Competing interests}

The authors declare that they have no competing interests.

Received: 4 February 2011 Accepted: 26 May 2011

Published: 26 May 2011

\section{References}

1. Schultz $A B$, Chen $C Y$, Edington DW: The cost and impact of health conditions on presenteeism to employers: a review of the literature. Pharmacoeconomics 2009, 27(5):365-378

2. Burton WN, Conti DH, Chen CY: The role of health risk factors and disease on worker productivity. J Occup Environ Health 1999, 41:863-877.
3. Schultz $A B$, Edington DW: Employee health and presenteeism: a systematic review. J Occup Rehabil 2007, 17(3):547-579.

4. Loeppke R, Hymel PA, Lofland JH, Pizzi LT, Konicki DL, Anstadt GW, Baase C, Fortuna J, Scharf T, American College of Occupational and Environmental Medicine: Health-related workplace productivity measurement: general and migraine-specific recommendations from the ACOEM Expert Panel. J Occup Environ Med 2003, 45(4):349-359.

5. Escorpizo R, Bombardier C, Boonen A, Hazes JMW, Lacaille D, Strand V, Beaton D: Worker productivity outcome measures in arthritis. I Rheum 2007, 34(6):1372-1380.

6. Naumanen P: Opinions of ageing workers on relative importance of health promotion. Int J Nurs Pract 2006, 12(6):352-358.

7. National Business Group on Health/Towers Watson: Staying@Work Report 2009/2010: The health and productivity advantage. TW-NA-2009-14891: Watson Wyatt Worldwide; 2010 [http://www.towerswatson.com/assets/pdf/ 648/The\%20Health\%20and\%20Productivity\%20Advantage\%20-\% 20Staying@Work\%20Study.pdf], Retrieved February 5, 2010.

8. Chapman LS: Meta-evaluation of worksite health promotion economic return studies: 2005 Update. Am J Health Promot 2005, 19(6):1-11.

9. Riedel JE, Lynch W, Baase C, Hymel P, Peterson KW: The effect of disease prevention and health promotion on workplace productivity: a literature review. Am J Health Promot 2001, 15(3):167-191.

10. Kuoppala J, Lamminpaa A, Husman P: Work health promotion, job wellbeing, and sickness absences - A systematic review and meta-analysis. J Occup Environ Med 2008, 50(11):1216-1227.

11. Pohjonen T, Ranta R: Effects of worksite physical exercise intervention on physical fitness, perceived health status, and work ability among home care workers: five-year follow-up. Prev Med 2001, 32(6):465-475.

12. Chen H, Blanc PD, Hayden ML, Bleecker ER, Chawla A, Lee JH: Assessing productivity loss and activity impairment in severe or difficult-to-treat asthma. Value Health 2008, 11(2):231-239.

13. Schultz $A B$, Edington DW: Metabolic syndrome in a workplace: Prevalence, co-morbidities, and economic impact. Metab Syndr Relat Disord 2009, 7(5):459-468.

14. Tang K, Pitts S, Solway S, Beaton D: Comparison of the psychometric properties of four at-work disability measures in workers with shoulder or elbow disorders. J Occup Rehab 2009, 19:142-154.

15. Goetzel RZ, Long SR, Ozminkowski RJ, Hawkins K, Wang S, Lynch W: Health, absence, disability, and presenteeism cost estimates of certain physical and mental health condition affecting U.S. employers. J Occup Environ Med 2004, 46(4):398-412.

16. Escorpizo R, Cieza A, Beaton D, Boonen A: Content comparison of worker productivity questionnaires in arthritis and musculoskeletal conditions using the International Classification of Functioning, Disability, and Health Framework. J Occup Rehab 2009, 19:382-397.

17. Lofland JH, Pizzi L, Frick KD: A review of health-related workplace productivity loss instruments. Pharmacoeconomics 2004, 22(3):165-184

18. Prasad $M$, Wahlquist $P$, Shikiar $R$, Shih $Y T$ : A review of self-report instruments measuring health-related work productivity. Pharmacoeconomics 2004, 22(4):225-244.

19. Beaton D, Bombardier C, Escorpizo R, Zhang W, Lacaille D, Boonen A, Osborne RH, Anis AH, Strand CV, Tugwell PS: Measuring worker productivity: Frameworks and measures. J Rheum 2009, 36(9):2100-2109.

20. Beaton DE, Tang K, Gignac MAM, Lacaille D, Badley EM, Anis AH, Bombardier C: Reliability, validity, and responsiveness of five at-work productivity measures in patients with rheumatoid arthritis or osteoarthritis. Arth Care Research 2010, 62(1):28-37.

21. Chen H, Blanc PD, Hayden ML, Bleecker ER, Chawla A, Lee JH: Assessing productivity loss and activity impairment in severe or difficult-to-treat asthma. Value Health 2008, 11(2):231-239.

22. Kessler RC, Ames M, Hymel PA, Loeppke R, McKenas DK, Richling DE, Stang PE, Ustun TB: Using the World Health Organization Health and Work Performance Questionnaire (HPQ) to evaluate the indirect workplace costs of illness. J Occup Environ Med 2004, 46 (6 suppl): S23-S37.

23. Mattke S, Balakrishnan A, Bergamo G, Newberry SJ: A review of methods to measure health-related productivity loss. Amer J Manag Care 2007, 13(4):211-217.

24. Lerner D, Amick BC, Rogers WH, Malspeis S, Bungay K, Cynn D: The Work Limitations Questionnaire. Med Care 2001, 39:72-85. 
25. Reilly MC, Zbrozek AS, Dukes EM: The validity and reproducibility of a work productivity and activity impairment instrument.

Pharmacoeconomics 1993, 4:353-365.

26. Wahlqvist P, Guyatt GH, Armstrong D, Degl'innocenti A, Heels-Ansdell D, ElDika S, Wiklund I, Fallone CA, Tanser L, Veldhuyzen van Zanten S, Austin P, Barkun AN, Chiba N, Schunemann HJ: The Work Productivity and Activity Impairment questionnaire for patients with gastroesophageal reflux disease (WPAI-GERD): Responsiveness to change and English language validation. PharmacoEconomics 2007, 25(5):385-396.

27. Koopman C, Pelletier KR, Murray JF, Sharda CE, Berger ML, Turpin RS, Hackleman P, Gibson P, Holmes DM, Bendel T: Stanford Presenteeism Scale: health status and employee productivity. J Occup Environ Med 2002, 44:14-20.

28. Pelletier KR: A review and analysis of the clinical and cost-effectiveness studies of comprehensive health promotion and disease management programs at the worksite: update VI 2000-2004. J Occup Environ Med 2005, 47(10):1051-1058.

29. Pelletier KR: A review and analysis of the clinical and cost-effectiveness studies of comprehensive health promotion and disease management programs at the worksite: Update VII 2004-2008. J Occup Environ Med 2009, 51(7):822-837.

30. Childress JM, Lindsay GM: National indications of increasing investment in workplace health promotion programs by large- and medium-size companies. N C Med J 2006, 67(6):449-452.

31. Goetzel RZ, Shechter D, Ozminkowski RJ, Marmet PF, Tabrizi MJ, Roemer EC Promising practices in employer health and productivity management efforts: findings from a benchmarking study. J Occup Environ Med 2007, 49(2):111-130.

32. Hillier D, Fewell F, Cann W, Shephard V: Wellness at work: enhancing the quality of our working lives. Int Rev Psychiatry 2005, 17(5):419-431.

33. Kuoppala J, Lamminpaa A, Liira J, Vainio H: Leadership, job well-being, and health effects - A systematic review and a meta-analysis. J Occup Environ Med 2008, 50(8):904-915.

34. Special Committee on Health, Productivity, and Disability Management: Healthy workforce/healthy economy: The role of health, productivity, and disability management in addressing the nation's health care crisis: Why an emphasis on the health of the workforce is vital to the health of the economy. J Occup Environ Med 2009, 51(1):114-119.

35. Terry PE, Seaverson EL, Grossmeier J, Anderson DR: Association between nine quality components and superior worksite health management program results. J Occup Environ Med 2008, 50(6):633-641.

36. Tompa E, Dolinschi R, de Oliveira C, Irvin E: A systematic review of occupational health and safety interventions with economic analyses. $J$ Occup Environ Med 2009, 51(9):1004-1023.

37. Micucci $\mathrm{S}$, Thomas $\mathrm{H}$ : The effectiveness of multi-faceted health promotion interventions in the workplace to reduce chronic disease. 2007 [http://www.ephpp.ca/PDF/2007_Workplace\%20Interventions\% 20Chronic\%20disease.pdf], Retrieved November 3, 2009.

38. Thomas BH, Ciliska D, Dobbins M, Micucci S: A process for systematically reviewing the literature: Providing the research evidence for public health nursing interventions. Worldviews Evid-Based Nurs 2004, Third Quarter:176-184.

39. Deeks JJ, Dinnes J, D'Amico R, Sowden AJ, Sakarovitch C, Song F, Petticrew M, Altman DG, International Stroke Trial Collaborative Group, European Carotid Surgery Trial Collaborative Group: Evaluating nonrandomized intervention studies. Health Tech Assess 2003, 7(27):1-173.

40. Slavin RE: Best evidence synthesis: an intelligent alternative to metaanalysis. J Clinical Epidem 1995, 48:9-18.

41. Nurminen E, Malmivaara A, Ilmarinen J, Ylöstalo P, Mutanen P, Ahonen G, Aro T: Effectiveness of a worksite exercise program with respect to perceived work ability and sick leaves among women with physical work. Scand J Work Environ Health 2002, 28(2):85-93.

42. Takao S, Tsutsumi A, Nishiuchi K, Mineyama S, Kawakami N: Effects of the job stress education for supervisors on psychological distress and job performance among their immediate subordinates: a supervisor-based randomized controlled trial. J Occup Health 2006, 48(6):494-503.

43. Block $G$, Sternfeld B, Block CH, Block TJ, Norris J, Hopkins D, Quesenberry CP, Husson G, Clancy HA: Development of Alive! (A Lifestyle Intervention Via Email), and its effect on health-related quality of life, presenteeism, and other behavioral outcomes: randomized controlled trial. J Med Internet Research 2008, 10(4):e43.
44. Dababneh AJ, Swanson N, Shell RL: Impact of added rest breaks on the productivity and well being of workers. Ergon 2001, 44(2):164-174.

45. de Boer AGEM, van Beek JC, Durinck J, Verbeek JHAM, van Dijk FJH: An occupational health intervention programme for workers at risk for early retirement; a randomised controlled trial. Occup Environ Med 2004, 61(11):924-929.

46. Mills PR, Kessler RC, Cooper J, Sullivan S: Impact of a health promotion program on employee health risks and work productivity. Am J Health Promot 2007, 22(1):45-53.

47. Rivilis I, Cole DC, Frazer MB, Kerr MS, Wells RP, Ibrahim S: Evaluation of a participatory ergonomic intervention aimed at improving musculoskeletal health. Am J Ind Med 2006, 49(10):801-810.

48. Tsutsumi A, Nagami M, Yoshikawa T, Kogi K, Kawakami N: Participatory intervention for workplace improvements on mental health and job performance among blue-collar workers: a cluster randomized controlled trial. J Occup Environ Med 2009, 51(5):554-563.

49. Viola $A U$, James $L M$, Schlangen $L$, Dijk DJ: Blue-enriched white light in the workplace improves self-reported alertness, performance and sleep quality. Scand J Work Environ Health 2008, 34(4):297-306.

50. Wang PS, Simon GE, Avorn J, Azocar F, Ludman EJ, McCulloch J, Petukhova MZ, Kessler RC: Telephone screening, outreach, and care management for depressed workers and impact on clinical and work productivity outcomes: a randomized controlled trial. JAMA 2007. 298(12):1401-1411.

51. IJzelenberg H, Meerding WJ, Burdorf A: Effectiveness of a back pain prevention program: a cluster randomized controlled trial in an occupational setting. Spine 2007, 32(7):711-719.

52. von Thiele Schwarz U, Lindfors P, Lundberg U: Health-related effects of worksite interventions involving physical exercise and reduced workhours. Scand J Work Environ Health 2008, 34(3):179-188.

53. Blangsted AK, Sogaard K, Hansen EA, Hannerz H, Sjogaard G: One-year randomized controlled trial with different physical-activity programs to reduce musculoskeletal symptoms in the neck and shoulders among office workers. Scand J Work Environ Health 2008, 34(1):55-65.

54. de Kraker H, de Korte EM, van Mil FLK, Rijs BP, Bongers PM: The effect of a feedback signal in a computer mouse on hovering behaviour, productivity, comfort and usability in a field study. Ergon 2008, 51(2):140-155.

55. Soler RE, Leeks KD, Razi S, Hopkins DP, Griffith M, Aten A, Chattopadhyay SK, Smith SC, Habarta N, Goetzel RZ, Pronk NP, Richling DE, Bauer DR, Buchanan LR, Florence CS, Koonin L, MacLean D, Grizzell JV, Walker AM: A systematic review of selected interventions for worksite health promotion. The assessment of health risks with feedback. Am J Prev Med 2010, 38(2S):S237-S262.

56. Koopmanschap M, Burdorf A, Jacob K, Meerding WJ, Brouwer W, \& Severens $\mathrm{H}$ : Measuring productivity changes in economic evaluation: Setting the research agenda. Pharmacoecon 2005, 23:47-54.

57. Kristensen TS: Intervention studies in occupational epidemiology. Occup Environ Med 2005, 62(3):205-210.

58. Moher D, Liberati A, Tetzlaff J, Altman DG, PRISMA Group: Preferred reporting items for systematic reviews and meta-analysis: the PRISMA statement. Ann Int Med 2009, 151(4):264-269.

59. Allen HM Jr, Borden S, Pikelny DB, Paralkary S, Slavin T, Bunn WB III: An intervention to promote appropriate management of allergies in a heavy manufacturing workforce: evaluating health and productivity outcomes. J Occup Environ Med 2003, 45(9):956-972

60. Burton WN, McCalister KT, Chen C, Edington DW: The association of health status, worksite fitness center participation, and two measures of productivity. J Occup Environ Med 2005, 47(4):343-351.

61. Galinsky TL, Swanson NG, Sauter SL, Hurrell JJ, Schleifer LM: A field study of supplementary rest breaks for data-entry operators. Ergonomics 2000, 43(5):622-638.

62. Galinsky T, Swanson N, Sauter S, Dunkin R, Hurrell J, Schleifer L: Supplementary breaks and stretching exercises for data entry operators: a follow-up field study. Am J Ind Med 2007, 50(7):519-527.

63. Harlow KC: The effectiveness of a problem resolution and brief counseling EAP intervention. Journal of Workplace Behavioral Health 2007 22(1):1-12.

64. Henning RA, Jacques P, Kissel GV, Sullivan AB, Alteras-Webb SM: Frequent short rest breaks from computer work: effects on productivity and wellbeing at two field sites. Ergonomics 1997, 40(1):78-91. 
65. Karazman R, Kloimuller I, Geissler H, Karazman-Morawetz I: "Effect typology" and Work Ability Index: Evaluating the success of health promotion in elder workforce. Experimental Aging Research 1999, 25(4):313-321.

66. Karazman R, Kloimuller I, Geissler H, Karazman-Morawetz I: Effects of ergonomic and health training on work interest, work ability and health in elderly public urban transport drivers. Int J Ind Ergon 2000, 25(5):503-511.

67. Larsson A, Karlqvist L, Gard G: Effects of work ability and health promoting interventions for women with musculoskeletal symptoms: a 9-month prospective study. BMC Musculoskelet Disord 2008, 9:105.

68. Loeppke R, Nicholson S, Taitel M, Sweeney M, Haufle V, Kessler RC: The impact of an integrated population health enhancement and disease management program on employee health risk, health conditions, and productivity. Popul Health Manag 2008, 11(6):287-296.

69. Low D, Gramlich M, Engram BW: Self-paced exercise program for office workers: impact on productivity and health outcomes. AAOHN journal: official journal of the American Association of Occupational Health Nurses 2007, 55(3):99-105.

70. Meenan R, Vogt T, Williams A, Stevens V, Albright C, Nigg C: Economic Evaluation of a Worksite Obesity Prevention and Intervention Trial Among Hotel Workers in Hawaii. J Occup Environ Med 2010, 52(1 Supplement):S8-S13.

71. Meijer EM, Frings-Dresen MHW, Sluiter JK: Effects of office innovation on office workers' health and performance. Ergonomics 2009, 52(9):1027-1038

72. Morales A, Martinez MM, Tasset-Tisseau A, Rey E, Baron-Papillon F, Follet A: Costs and benefits of influenza vaccination and work productivity in a Columbian company from the employer's perspective. Value in Health 2004, 7(433):441.

73. Mushet GR, Miller D, Clements B, Pait G, Gutterman DL: Impact of sumatriptan on workplace productivity, nonwork activities, and healthrelated quality of life among hospital employees with migraine. Headache 1996, 36(3):137-143.

74. Pelletier B, Boles M, Lynch W: Change in health risks and work productivity over time. J Occup Environ Med 2004, 46(7):746-754.

75. Pohjonen T, Ranta R: Effects of worksite physical exercise intervention on physical fitness, perceived health status, and work ability among home care workers: five-year follow-up. Preventive medicine 2001, 32(6):465-475

76. Puig-Ribera A, McKenna J, Gilson N, Brown WJ: Change in work day step counts, wellbeing and job performance in Catalan university employees: a randomised controlled trial. Promot Educ 2008, 15(4):11-16.

77. Samad AH, Usul MHBHJ, Zakaria D, Ismail R, Tasset-Tisseau A, BaronPapillon F, Follet A: Workplace vaccination against influenza in Malaysia: Does the employer benefit? J Occup Health 2006, 48(1):1-10.

78. Slot T, Charpentier K, Dumas G, Delisle A, Leger A, Plamondon A: Evaluation of forearm support provided by the Workplace Board on perceived tension, comfort and productivity in pregnant and nonpregnant computer users. Work 2009, 34(1):67-77.

79. Umanodan R, Kobayashi Y, Nakamura M, Kitaoka-Higashiguchi K, Kawakami N, Shimazu A: Effects of a worksite stress management training program with six short-hour sessions: a controlled trial among Japanese employees. J Occup Health 2009, 51(4):294-302.

80. Vicente-Herrero T, Burke TA, Lainez MJ: The impact of a worksite migraine intervention program on work productivity, productivity costs, and nonworkplace impairment among Spanish postal service employees from an employer perspective. Curr Med Res Opin 2004, 20(11):1805-1814.

81. Watson DT, Long WJ, Yen D, Pichora DR: Health promotion program: a resident well-being study. lowa Orthop J 2009, 29:83-87.

82. Laestadius JG, Ye J, Cai X, Ross S, Dimberg L, Klekner M: The proactive approach - is it worthwhile? A prospective controlled ergonomic intervention study in office workers. J Occup Environ Med 2009, 51(10):1116-1124.

83. Anderzen I, Arnetz BB: The impact of a prospective survey-based workplace intervention program on employee health, biologic stress markers, and organizational productivity. J Occup Environ Med 2005, 47(7):671-682.

84. Earle-Richardson G, Jenkins PL, Strogatz D, Bell EM, Sorensen JA, May JJ: Orchard evaluation of ergonomically modified apple bucket. J Agromed 2006, 11(3-4):95-105

85. Faucett J, Meyers J, Miles J, Janowitz I, Fathallah F: Rest break interventions in stoop labor tasks. Appl Ergon 2007, 38(2):219-226.
86. Greene BL, Miller JD, Brown TM, Harshman RS, Richerson GT, Doyle JJ: Economic impact of the BP DownShift Program on blood pressure control among commercial driver license employees. Journal of Occupational and Environmental Medicine 2009, 51(5):542-553.

87. Guppy A, Marsden J: Assisting employees with drinking problems: changes in mental health, job perceptions and work performance. Work Stress 1997, 11(4):341-350.

88. Page MJ, Paramore LC, Doshi D, Rupnow MF: Evaluation of resource utilization and cost burden before and after an employer-based migraine education program. Journal of Occupational and Environmental Medicine 2009, 51(2):213-220.

89. Pedersen MT, Blangsted AK, Andersen LL, Jørgensen MB, Hansen EA, Sjøgaard G: The effect of worksite physical activity intervention on physical capacity, health, and productivity: a 1-year randomized controlled trial. J Occup Environ Med 2009, 51(7):759-770.

90. Yeow PHP, Nath Sen R: Quality, productivity, occupational health and safety and cost effectiveness of ergonomic improvements in the test workstations of an electronic factory. International Journal of Industrial Ergonomics 2003, 32:147-163.

91. van den Heuvel SG, de Looze MP, Hildebrandt VH, Thé KH: Effects of software programs stimulating regular breaks and exercises on workrelated neck and upper-limb disorders. Scand J Work Environ Health 2003, 29(2):106-116

92. Loeppke R, Taitel M, Richling D, Parry T, Kessler RC, Hymel P, Konicki D: Health and productivity as a business strategy. J Occup Environ Med 2007, 49(7):712-721.

93. Chapman LS: Presenteeism and its role in worksite health promotion. Am J Health Promot 2005, $19(4$ suppl):1-8.

\section{Pre-publication history}

The pre-publication history for this paper can be accessed here:

http://www.biomedcentral.com/1471-2458/11/395/prepub

\section{doi:10.1186/1471-2458-11-395}

Cite this article as: Cancelliere et al:: Are workplace health promotion programs effective at improving presenteeism in workers? a systematic review and best evidence synthesis of the literature. BMC Public Health 2011 11:395.

\section{Submit your next manuscript to BioMed Central and take full advantage of:}

- Convenient online submission

- Thorough peer review

- No space constraints or color figure charges

- Immediate publication on acceptance

- Inclusion in PubMed, CAS, Scopus and Google Scholar

- Research which is freely available for redistribution

Submit your manuscript at www.biomedcentral.com/submit
C Biomed Central 